\title{
Aproveitamento pelo milho do nitrogênio amoniacal de dejetos líquidos de suínos em plantio direto e preparo reduzido do solo
}

\author{
Sandro José Giacomini ${ }^{(1)}$, Celso Aita(1), Claudia Pozzi Jantalia ${ }^{(2)}$ e Segundo Urquiaga ${ }^{(2)}$ \\ (1)Universidade Federal de Santa Maria, Centro de Ciências Rurais, Departamento de Solos, Caixa Postal 221, CEP 97105-900 Santa Maria, RS. \\ E-mail: sjgiacomini@smail.ufsm.br, celsoaita@gmail.com ${ }^{(2)}$ Embrapa Agrobiologia, Caixa Postal 74.505, CEP 23890-000 Seropédica, RJ. \\ E-mail: claudia@cnpab.embrapa.br, urquiaga@cnpab.embrapa.br
}

Resumo - O objetivo deste trabalho foi avaliar o aproveitamento do $\mathrm{N}$ amoniacal de dejetos líquidos de suínos (DLS) pela cultura do milho (Zea mays). O experimento foi conduzido em Argissolo Vermelho distrófico arênico. Os tratamentos avaliados consistiram da aplicação ou não de DLS sobre resíduos culturais de aveia, em plantio direto e preparo reduzido do solo. Para quantificar o destino do $\mathrm{N}$ amoniacal aplicado, a fração amoniacal dos DLS foi enriquecida com $\left({ }^{15} \mathrm{NH}_{4}\right)_{2} \mathrm{SO}_{4}$. O aproveitamento do $\mathrm{N}$ amoniacal dos DLS pelo milho foi de apenas $15,3 \%$ e não diferiu com o uso do DLS em plantio direto ou em preparo reduzido do solo. $\mathrm{Na}$ maturação fisiológica do milho, a quantidade de ${ }^{15} \mathrm{~N}$ dos DLS recuperada no solo, até a profundidade de $120 \mathrm{~cm}$, e na planta (parte aérea+grãos +raízes) correspondeu a $49,6 \%$ do ${ }^{15} \mathrm{~N}$ aplicado. A fração de $\mathrm{N}$ orgânico dos DLS e a matéria orgânica do solo foram as principais fontes de $\mathrm{N}$ para a cultura do milho.

Termos para indexação: Zea mays, adubação orgânica, isótopo ${ }^{15} \mathrm{~N}$, recuperação de $\mathrm{N}$.

\section{Corn utilization of ammoniacal nitrogen from pig slurry in no-tillage and reduced tillage}

\begin{abstract}
The objective of this work was to evaluate corn (Zea mays) utilization of ammoniacal $\mathrm{N}$ from pig slurry (PS). A field experiment was carried out in a typic Hapludalf. The treatments consisted of the application or not of PS on oat straw, in no-tillage and reduced tillage planting systems. In order to quantify the destination of applied ammoniacal $\mathrm{N}$ from the PS, the ammoniacal fraction was enriched with $\left({ }^{15} \mathrm{NH}_{4}\right)_{2} \mathrm{SO}_{4}$. The utilization of ammoniacal $\mathrm{N}$ from pig slurry by corn crop was of $15.3 \%$ and did not differ between no-tillage and reduced tillage soil systems. At corn physiological maturity, the amount of ${ }^{15} \mathrm{~N}$ recovered from the soil, at 120-cm depth, and from the plant (grain + shoot + roots) was $49.6 \%$ of the ${ }^{15} \mathrm{~N}$ applied with pig slurry. The organic $\mathrm{N}$ fractions from pig slurry and from soil organic matter were the main sources of $\mathrm{N}$ for corn.
\end{abstract}

Index terms: Zea mays, organic fertilization, ${ }^{15} \mathrm{~N}$ isotope, $\mathrm{N}$ recovery.

\section{Introdução}

$\mathrm{O}$ efeito dos dejetos líquidos de suínos sobre a produtividade das culturas comerciais está relativamente bem documentado no Brasil, tanto no sistema convencional de preparo do solo, com incorporação dos dejetos ao solo (Scherer, 1998), como no sistema plantio direto (Basso, 2003). Na maioria dos trabalhos que envolvem o uso desse material orgânico no cultivo de milho, tem-se observado aumento significativo no acúmulo de $\mathrm{N}$ pela planta e na produtividade de grãos da cultura (Basso, 2003; Giacomini \& Aita, 2008).

O potencial fertilizante dos dejetos líquidos de suínos é frequentemente atribuído à fração amoniacal presente nesse material orgânico, que perfaz aproximadamente $50 \%$ do N total. Trabalhos em que a fração amoniacal dos dejetos líquidos foi enriquecida com ${ }^{15} \mathrm{~N}$ mostram que de 15 a $50 \%$ do $\mathrm{N}$ contido nessa fração foi recuperado no cultivo subsequente à aplicação dos dejetos (Paul \& Beauchamp, 1995; Morvan et al., 1997; Sorensen \& Amato, 2002; Chantigny et al., 2004). Parte do N amoniacal não aproveitado pelas culturas permanece no solo na forma orgânica, e parte é perdida por processos de volatilização, lixiviação e desnitrificação (Morvan et al., 1997; Sorensen \& Amato, 2002).

$\mathrm{O}$ destino do $\mathrm{N}$ amoniacal aplicado com os dejetos líquidos de suínos depende da modalidade de sua aplicação ao solo. Ao comparar a aplicação de dejetos líquidos de suínos ( $100 \mathrm{~kg} \mathrm{ha}^{-1} \mathrm{de} \mathrm{N}$ amoniacal marcado $\operatorname{com}^{15} \mathrm{~N}$ ), com e sem incorporação ao solo, Sorensen \& Amato (2002) verificaram que o aproveitamento do N amoniacal pela cevada foi de $14 \mathrm{e} 27 \%$, respectivamente. 
Nesse mesmo estudo, os autores verificaram que a recuperação do $\mathrm{N}$ amoniacal aumentou de $35 \%$, com a aplicação dos dejetos em superfície, para 55\% quando os dejetos foram incorporados ao solo. Os menores valores de recuperação do $\mathrm{N}$ amoniacal, com a aplicação dos dejetos na superfície do solo, foram atribuídos ao aumento das perdas de $\mathrm{N}$ por volatilização de amônia nesse sistema.

No Brasil, não foram encontradas informações de pesquisa em que o isótopo ${ }^{15} \mathrm{~N}$ tivesse sido utilizado para avaliar o destino da fração amoniacal aplicada ao solo por meio de dejetos de suínos. Essa técnica tem se restringido à avaliação da eficiência da uréia e de outros fertilizantes nitrogenados minerais no fornecimento de $\mathrm{N}$ às culturas (Duete et al., 2008). Para melhorar a eficiência de uso de $\mathrm{N}$ dos dejetos líquidos de suínos, pelo milho, é necessário conhecer melhor o destino da fração amoniacal dos dejetos no sistema solo-planta, especialmente em sistema plantio direto, em que as perdas de $\mathrm{N}$ por volatilização de amônia nas primeiras horas após a sua aplicação são elevadas (Port et al., 2003).

O objetivo deste trabalho foi avaliar o aproveitamento pela cultura do milho do $\mathrm{N}$ amoniacal de dejetos líquidos de suínos (DLS), aplicados sobre resíduos culturais de aveia, em plantio direto e preparo reduzido do solo.

\section{Material e Métodos}

O trabalho foi realizado de novembro de 2002 a março de 2003, na área experimental do Departamento de Solos da Universidade Federal de Santa Maria (RS), em Argissolo Vermelho distrófico arênico (Sistema Brasileiro de Classificação de Solos, 1999). No início do experimento, a camada superficial do solo $(0-10 \mathrm{~cm})$ apresentou as seguintes características físicas e químicas: $150 \mathrm{~g} \mathrm{~kg}^{-1}$ de argila; $\mathrm{pH}$ em água de 5,2; índice SMP de 6,5; 16,2 $\mathrm{mg} \mathrm{L}^{-1}$ de P; 0,12 cmol $_{\mathrm{c}}$ de $\mathrm{K} ; 0,1 \mathrm{cmol}_{\mathrm{c}} \mathrm{L}^{-1}$ de $\mathrm{Al}^{3+} ; 2,5 \mathrm{cmol}_{\mathrm{c}} \mathrm{L}^{-1}$ de $\mathrm{Ca}^{2+}$; $0,6 \mathrm{cmol}_{\mathrm{c}} \mathrm{L}^{-1}$ de $\mathrm{Mg}^{2+} ; 2,3 \mathrm{cmol}_{\mathrm{c}} \mathrm{L}^{-1}$ de $\mathrm{H}+\mathrm{Al}^{3+}$; 3,3 cmol $_{\mathrm{c}} \mathrm{L}^{-1}$ de CTC efetiva; saturação de $\mathrm{Al}$ de $3 \%$; saturação por bases (V) de $57 \%$; e $18 \mathrm{~g} \mathrm{~kg}^{-1}$ de matéria orgânica (MO).

$\mathrm{O}$ delineamento experimental utilizado foi o de blocos ao acaso, com quatro repetições. Em parcelas de $5 \times 4 \mathrm{~m}$, com palha de aveia na superfície do solo, foram avaliados os seguintes tratamentos: $\mathrm{T} 1$ - dejetos líquidos de suínos (DLS) aplicados sobre a palha, em plantio direto; T2 - DLS aplicados sobre a palha, com incorporação parcial ao solo, em preparo reduzido; T3 - palha de aveia na superfície do solo, em plantio direto; e T4 - palha de aveia com incorporação parcial ao solo, em preparo reduzido. Os DLS foram aplicados na dose de $64 \mathrm{~m}^{3}$ ha-1 e distribuídos manualmente sobre a palha de aveia-preta (equivalente a $3.600 \mathrm{~kg} \mathrm{ha}^{-1} \mathrm{de}$ matéria seca), em 3/11/2002, um dia após o manejo da aveia com rolo-faca. Nos tratamentos com preparo reduzido, a incorporação parcial da palha e da mistura de palha e DLS ao solo foi realizada com uma grade de discos hidráulica, três horas após a aplicação dos dejetos. A grade possuía 24 discos com diâmetro de $50 \mathrm{~cm}$, e o trabalho de incorporação dos materiais orgânicos foi efetuado à profundidade de até $7 \mathrm{~cm}$.

No centro das parcelas dos tratamentos com o uso de DLS, foram demarcadas microparcelas de 1,8x2,0 $\mathrm{m}$, onde foram aplicados DLS com fração amoniacal enriquecida com ${ }^{15} \mathrm{~N}$. O enriquecimento da fração amoniacal dos dejetos foi realizado pela adição de uma solução de sulfato de amônio com $10 \%$ de átomos de ${ }^{15} \mathrm{~N}$ em excesso. A mistura dos dejetos com a solução enriquecida com ${ }^{15} \mathrm{~N}$ foi realizada em um recipiente de plástico com capacidade para $40 \mathrm{~L}$, por meio da agitação manual e vigorosa da mistura durante $5 \mathrm{~min}$. A aplicação e a incorporação dos DLS enriquecidos, ao solo das microparcelas foram realizadas ao mesmo tempo que a aplicação de DLS sem enriquecimento no restante das parcelas.

Em razão da necessidade de se adicionar $\left({ }^{15} \mathrm{NH}_{4}\right)_{2} \mathrm{SO}_{4}$, para enriquecer com ${ }^{15} \mathrm{~N}$ a fração amoniacal dos dejetos, a quantidade de $\mathrm{N}$ amoniacal aplicada em cada microparcela foi $36 \%$ maior que no restante da parcela, onde foram aplicados os DLS com a fração do $\mathrm{N}$ amoniacal não marcado. Apesar disso, os DLS enriquecidos com $\left({ }^{15} \mathrm{NH}_{4}\right)_{2} \mathrm{SO}_{4}$ apresentaram quantidade de $\mathrm{N}$ amoniacal dentro da faixa de $40-60 \%$ do N total, obtida por Scherer et al. (1996), ao analisar 98 amostras de dejetos líquidos de suínos.

A matéria seca dos dejetos foi determinada por meio de sua secagem a $65^{\circ} \mathrm{C}$ em estufa, até massa constante. Adeterminação do $\mathrm{pH}$ dos DLS foirealizada diretamente em uma alíquota de aproximadamente $60 \mathrm{~mL}$ (Tedesco et al., 1995). No material seco e moído, foi determinado o teor de C orgânico (Tedesco et al., 1995). O N total foi determinado a partir de digestão úmida dos DLS, e o $\mathrm{N}$ amoniacal foi determinado por destilação em arraste 
a vapor, do tipo semimicrokjeldhal. Essas análises de $\mathrm{N}$ foram realizadas sem a secagem prévia dos dejetos, conforme descrito em Aita et al. (2007). O destilado foi captado em solução de $\mathrm{H}_{2} \mathrm{SO}_{4}$ a $0,2 \mathrm{~mol} \mathrm{~L}^{-1}$, e depois foi titulado o excesso de ácido com $\mathrm{NaOH}$ a $0,1 \mathrm{~mol} \mathrm{~L}^{-1}$. Após a titulação, a solução foi acidificada e submetida à secagem a $65^{\circ} \mathrm{C}$. No precipitado resultante, foi analisado o excesso isotópico de ${ }^{15} \mathrm{~N}$, por espectrometria de massa, na Embrapa Agrobiologia, RJ. Após a adição do $\left({ }^{15} \mathrm{NH}_{4}\right)_{2} \mathrm{SO}_{4}$, a fração amoniacal dos dejetos apresentou $2,27 \%$ de átomos de ${ }^{15} \mathrm{~N}$ em excesso.

A produção de massa de matéria seca da parte aérea da aveia foi determinada por ocasião da maturação fisiológica da cultura (30/10/2002). O material coletado foi seco a $65^{\circ} \mathrm{C}$ até massa constante, pesado e, posteriormente, moído e analisado quanto aos teores de nitrogênio total $(\mathrm{N})$ e carbono orgânico $(\mathrm{C})$, conforme Tedesco et al. (1995). As características da palha e dos DLS, bem como as quantidades adicionadas ao solo, estão apresentadas na Tabela 1.

A semeadura do milho (Pioneer 30F33) foi realizada cinco dias após a aplicação dos dejetos (8/11/2002) com semeadora para plantio direto, sem adição de fertilizantes químicos. O espaçamento entre linhas foi de $0,9 \mathrm{~m}$, com população final de aproximadamente 55 mil plantas ha ${ }^{-1}$. Cada microparcela consistiu de três fileiras de milho com $2 \mathrm{~m}$ de comprimento, no total de 30 plantas. O controle de plantas daninhas foi efetuado 15 dias após a germinação do milho, com aplicação da mistura de herbicidas nicosulfuron $\left(40 \mathrm{~g} \mathrm{ha}^{-1}\right.$ de i.a. $) \mathrm{e}$ ametryne (2.000 $\mathrm{g} \mathrm{ha}^{-1}$ de i.a.). Durante o ciclo da cultura do milho, foram realizadas irrigações suplementares por pivô central. As temperaturas médias diárias e a precipitação pluvial diária durante a condução do experimento estão na Figura 1.

$\mathrm{O}$ acúmulo de $\mathrm{N}$ pelo milho foi avaliado quando as plantas estavam no estádio de maturação fisiológica.
Para isso, foram coletadas cinco plantas de milho na área útil das parcelas dos tratamentos sem DLS, e cinco plantas da linha central de cada microparcela com aplicação de DLS enriquecido com ${ }^{15} \mathrm{~N}$. Essas plantas foram separadas nos seguintes componentes: grãos, sabugos e colmos+folhas+palha das espigas. A massa de matéria seca de cada componente foi obtida pela secagem em estufa a $65^{\circ} \mathrm{C}$, até massa constante. $\mathrm{O}$ material seco foi pesado, moído em um triturador de forragens, subamostrado e moído novamente em moinho Willey, tendo-se passado o material em peneira de 40 mesh. No tecido vegetal do milho, foram determinados os teores de $\mathrm{N}$ total (Tedesco et al., 1995). O excesso isotópico em ${ }^{15} \mathrm{~N}$ de cada parte da planta foi determinado por espectrometria de massa na Embrapa Agrobiologia (Marshall \& Whiteway, 1985). A quantidade de $\mathrm{N}$ acumulada pela parte aérea do milho representou a soma do $\mathrm{N}$ total de todos os componentes da planta avaliados.

Após a coleta das plantas de milho nas microparcelas, foram abertas trincheiras perpendiculares à fileira central, cujas dimensões foram de $120 \mathrm{~cm}$ de largura (60 $\mathrm{cm}$ para cada lado da fileira de milho), $120 \mathrm{~cm}$ de comprimento no sentido da fileira e $150 \mathrm{~cm}$ de profundidade. Em cada trincheira, na parede perpendicular à fileira de milho, foram coletadas amostras deformadas de solo nas seguintes camadas: 0-10, 10-20, 20-30, 30-40, 40-60, 60-80, 80-100 e $100-120 \mathrm{~cm}$. De cada camada, foi coletada uma fatia de solo com $45 \mathrm{~cm}$ de largura, a partir da fileira central de milho, e com $20 \mathrm{~cm}$ no sentido do comprimento da fileira de milho. As amostras de solo foram acondicionadas em sacos de plástico, tendo-se retirado uma subamostra de solo para secagem ao ar. O restante de cada amostra foi passado em peneira com malha de $1 \mathrm{~mm}$, com auxílio de água corrente. As raízes que permaneceram sobre a peneira foram colocadas para

Tabela 1. Composição química dos dejetos líquidos de suínos e da palha de aveia-preta e quantidades de massa de matéria seca (MS), carbono (C) e nitrogênio (N) adicionadas ao solo com os dois materiais orgânicos.

\begin{tabular}{|c|c|c|c|c|c|c|c|}
\hline Material orgânico & $\mathrm{MS}^{(1)}$ & $\mathrm{C}$ & $\mathrm{N}$ total & $\mathrm{N}$ amoniacal & $\mathrm{N}$ orgânico & $\mathrm{C} / \mathrm{N}$ & $\mathrm{pH}$ \\
\hline \multicolumn{8}{|c|}{ Composição química } \\
\hline Palha de aveia & 1.000 & 425,3 & 10,40 & $-(2)$ & - & 40,9 & - \\
\hline Dejetos líquidos & 46 & 9,7 & 2,53 & 1,24 & 1,29 & 3,8 & 7,9 \\
\hline \multicolumn{8}{|c|}{ Quantidades adicionadas } \\
\hline Palha de aveia & 3.600 & 1.531 & 37 & - & - & - & - \\
\hline Dejetos líquidos & 2.925 & 617 & 161 & 78,9 & 82,1 & - & - \\
\hline
\end{tabular}

${ }^{(1)}$ A composição dos dejetos refere-se à base úmida e a da palha, à base seca. ${ }^{(2)}$ Não determinado. 
secar em estufa a $65^{\circ} \mathrm{C}$, até massa constante, para a obtenção da massa de matéria seca de raízes. Após a moagem, determinou-se o teor de $\mathrm{N}$ total e o excesso isotópico em ${ }^{15} \mathrm{~N}$, conforme descrito anteriormente para o tecido vegetal da parte aérea do milho.

As subamostras de solo, secas ao ar por cinco dias, foram peneiradas (malha com diâmetro de $2 \mathrm{~mm}$ ) e, em seguida, moídas em gral para posterior análise do teor de $\mathrm{N}$ total (Tedesco et al., 1995) e do excesso isotópico em ${ }^{15} \mathrm{~N}$. Com base na concentração de $\mathrm{N}$ total do solo de cada camada e nos valores de densidade do solo, calculou-se a quantidade de $\mathrm{N}$ total em cada camada, até $120 \mathrm{~cm}$ de profundidade.

Os cálculos do aproveitamento pelo milho e da recuperação no solo do $\mathrm{N}$ amoniacal, aplicado com os dejetos líquidos de suínos, foram realizados conforme descrito em Powlson \& Barraclough (1993). Para o cálculo da percentagem do N no milho (parte aérea e raízes) ou no solo (PNpad) proveniente do $\mathrm{N}$ amoniacal dos dejetos, foi utilizada a seguinte equação: $\mathrm{PNpad}=100(\mathrm{~A} / \mathrm{B})$, em que A é o excesso isotópico em ${ }^{15} \mathrm{~N}$ do $\mathrm{N}$ total no milho ou no solo, e B é o excesso isotópico em ${ }^{15} \mathrm{~N}$ do $\mathrm{N}$ amoniacal dos dejetos aplicados.

A quantidade de $\mathrm{N}$ no milho ou no solo proveniente do $\mathrm{N}$ amoniacal dos dejetos (QNpad), em $\mathrm{kg} \mathrm{ha}^{-1}$, foi calculada a partir da equação:

$\mathrm{QNpad}=(\mathrm{PNpad} \times \mathrm{QNt}) / 100$, em que $\mathrm{QNt}$ é a quantidade total de $\mathrm{N}$ no milho ou no solo $\left(\mathrm{kg} \mathrm{ha}^{-1}\right)$.

Para o cálculo do aproveitamento pelo milho e da recuperação do $\mathrm{N}$ aplicado com o $\mathrm{N}$ amoniacal dos dejetos (RNad), em percentagem, utilizou-se a

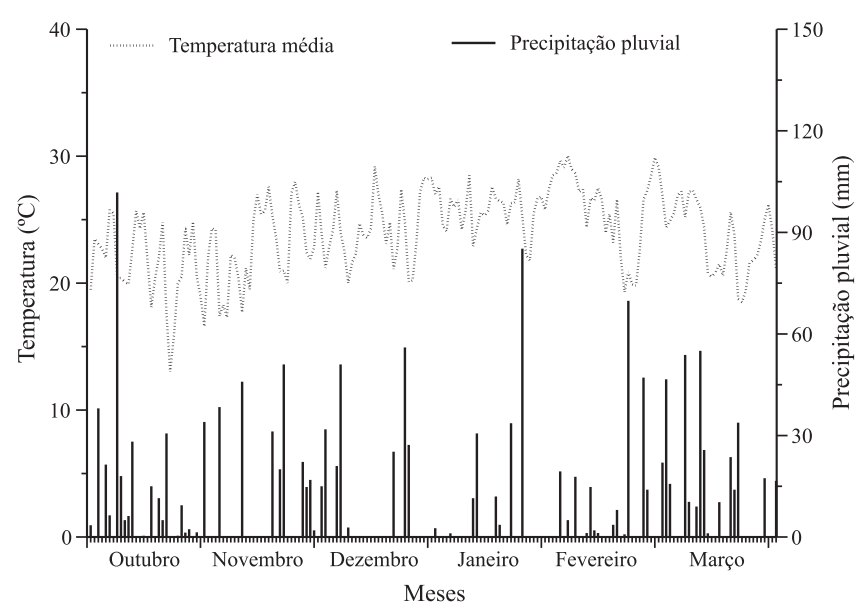

Figura 1. Temperaturas médias diárias e precipitação pluvial diária durante a condução do experimento. equação: $\mathrm{RNad}=100$ (QNpad/QNad), em que QNad é a quantidade de $\mathrm{N}$ aplicada com o $\mathrm{N}$ amoniacal dos dejetos $\left(\mathrm{kg} \mathrm{ha}^{-1}\right)$.

Para estimar a contribuição do $\mathrm{N}$ orgânico presente no DLS no fornecimento de $\mathrm{N}$ ao milho, utilizaram-se os dados de aproveitamento do ${ }^{15} \mathrm{~N}$ amoniacal, nas microparcelas, e as quantidades de $\mathrm{N}$ total acumuladas pelo milho nas parcelas sem o aporte de dejetos líquidos e nas microparcelas. A quantidade de $\mathrm{N}$ acumulada na parte aérea do milho, proveniente do $\mathrm{N}$ orgânico dos dejetos (QNpod), em $\mathrm{kg} \mathrm{ha}^{-1}$, foi estimada pela equação: QNpod = QNpm - QNpad - QNps, em que QNpm é a quantidade de $\mathrm{N}$ na parte aérea do milho, nas microparcelas $\left(\mathrm{kg} \mathrm{ha}^{-1}\right)$; QNps é a quantidade de $\mathrm{N}$ na parte aérea do milho proveniente do solo, nas parcelas sem o uso de dejetos $\left(\mathrm{kg} \mathrm{ha}^{-1}\right)$ - nesse cálculo, considera-se que o QNps é igual nas parcelas sem o uso dos dejetos e nas microparcelas. Esta estimativa pressupõe que os dejetos não afetam a taxa de mineralização do $\mathrm{N}$ da matéria orgânica do solo (efeito "priming") e da palha de aveia. No caso de ocorrência de efeito "priming" positivo, o QNps será maior nas microparcelas, e a QNpod pode ser superestimada; o inverso será verdadeiro se o efeito "priming" for negativo.

A quantidade total de $\mathrm{N}$ no sistema solo-planta proveniente da fração amoniacal dos dejetos foi obtida pela soma das quantidades de $\mathrm{N}$ na parte aérea e nas raízes do milho e das quantidades de $\mathrm{N}$ em cada camada do solo, derivadas do $\mathrm{N}$ amoniacal dos dejetos, estimadas diretamente pela metodologia isotópica. Os dados obtidos foram submetidos à análise de variância, e as médias de tratamentos foram comparadas pelo teste $\mathrm{t}$ de Student, a $5 \%$ de probabilidade.

\section{Resultados e Discussão}

A quantidade de $\mathrm{N}$ acumulada na parte aérea e nas raízes da cultura do milho após a aplicação de DLS não foi influenciada significativamente pelo tipo de preparo do solo (Tabela 2). Na média das duas modalidades de aplicação, $87,5 \%$ do $\mathrm{N}$ total acumulado pelo milho, no estádio de maturação fisiológica, encontrava-se na parte aérea, e $12,5 \%$, nas raízes.

A quantidade de $\mathrm{N}$ proveniente do $\mathrm{N}$ amoniacal dos dejetos líquidos de suínos (QNpad), que foi encontrada no solo, nas raízes e na parte aérea do milho, também não diferiu entre os tratamentos em plantio direto e 
com preparo reduzido do solo (Tabela 2). Considerandose a média desses dois sistemas, a quantidade de ${ }^{15} \mathrm{~N}$ encontrada no perfil do solo $(0-120 \mathrm{~cm})$ foi de $34,3 \%$ do ${ }^{15} \mathrm{~N}$ aplicado. $\mathrm{O}$ aproveitamento do ${ }^{15} \mathrm{~N}$ pelas plantas foi de $15,3 \%$, sendo $1,5 \%$ nas raízes e $13,8 \%$ nas parte aéreas. Assim, a quantidade recuperada no solo e nas plantas do total de ${ }^{15} \mathrm{~N}$ aplicado foi de $49,6 \%$.

$\mathrm{O}$ valor médio de $13,8 \%$ para o aproveitamento pela parte aérea do milho do $\mathrm{N}$ amoniacal do DLS (RNad), obtido no presente trabalho, foi próximo do valor de $15 \%$ encontrado por Paul \& Beauchamp (1995), após terem incorporado ao solo $100 \mathrm{~kg} \mathrm{ha}^{-1}$ de $\mathrm{N}$ amoniacal marcado com ${ }^{15} \mathrm{~N}$, com dejetos de suínos, para o cultivo do milho. Também com dejetos de suínos, cujas frações orgânica e mineral foram enriquecidas com ${ }^{15} \mathrm{~N}$ por meio da alimentação dada aos animais, Chantigny et al. (2004) verificaram que o aproveitamento pelo milho do $\mathrm{N}$ aplicado com os dejetos diminuiu de $50 \%$, em solo arenoso, para $20 \%$ em solo argiloso. O maior aproveitamento do $\mathrm{N}$ dos dejetos observado por esses autores não deve estar relacionado ao fato de o $\mathrm{N}$ orgânico dos dejetos, nesses trabalhos, também ter sido enriquecido $c{ }^{15} \mathrm{~N}$.

Tabela 2. Quantidade de $\mathrm{N}$ acumulada pelo milho (QNt), quantidade de $\mathrm{N}$ proveniente do $\mathrm{N}$ amoniacal dos dejetos líquidos de suínos (QNpad) e recuperação do $\mathrm{N}$ amoniacal dos dejetos líquidos de suínos ( $\mathrm{RNad}$ ), na parte aérea (palha+grãos) e raízes da cultura do milho e no solo $(0-120 \mathrm{~cm})$, após o uso de dejetos de suínos, em plantio direto e preparo reduzido ${ }^{(1)}$.

\begin{tabular}{|c|c|c|c|}
\hline Local de avaliação & Plantio direto & Preparo reduzido & Média \\
\hline & \multicolumn{3}{|c|}{ QNt $\left(\mathrm{kg} \mathrm{ha}^{-1}\right)$} \\
\hline Parte aérea ${ }^{(2)}$ & 91,7 & 104,0 & 97,9 \\
\hline Raízes & 13,8 & 14,3 & 14,1 \\
\hline \multirow[t]{2}{*}{ Total } & 105,5 & 118,3 & 112,0 \\
\hline & \multicolumn{3}{|c|}{ QNpad $\left(\mathrm{kg} \mathrm{ha}^{-1}\right)$} \\
\hline Parte aérea & 11,7 & 10,1 & 10,9 \\
\hline Raízes & 1,5 & 0,9 & 1,2 \\
\hline Solo & 28,1 & 26,0 & 27,1 \\
\hline \multirow[t]{2}{*}{ Total } & 41,3 & 37,0 & 39,2 \\
\hline & \multicolumn{3}{|c|}{ RNad (\%) } \\
\hline Parte aérea & 14,8 & 12,8 & 13,8 \\
\hline Raízes & 1,9 & 1,1 & 1,5 \\
\hline Solo & 35,6 & 33,0 & 34,3 \\
\hline Total & 52,3 & 46,8 & 49,6 \\
\hline \multicolumn{4}{|c|}{$\begin{array}{l}\text { (1) Não foi observada diferença significativa entre as médias dos sistemas de } \\
\text { plantio, em nenhum dos locais avaliados, pelo teste t a } 5 \% \text { de probabilidade. } \\
{ }^{(2)} \text { A quantidade de } \mathrm{N} \text { acumulada na parte aérea do milho, nos tratamentos sem } \\
\text { dejetos, em plantio direto e no preparo reduzido do solo foi de } 45,6 \mathrm{~kg} \mathrm{ha}^{-1} \\
\text { e } 39,9 \mathrm{~kg} \mathrm{ha}^{-1} \text {, respectivamente. }\end{array}$} \\
\hline
\end{tabular}

Essa fração deve ter contribuído pouco para o fornecimento de $\mathrm{N}$ ao milho, pois representava apenas $10 \%$ do $\mathrm{N}$ total aplicado com os dejetos.

Os resultados obtidos em trabalhos de avaliação sobre o aproveitamento do $\mathrm{N}$ amoniacal de DLS, medido pela técnica do ${ }^{15} \mathrm{~N}$, indicaram que a incorporação ao solo resultou em maior RNad pelas culturas em relação ao uso sem incorporação. Sorensen \& Amato (2002) compararam o manejo da aplicação de DLS pela injeção ao solo com a incorporação ou com a aplicação na superfície do solo, e verificaram que a RNad de $100 \mathrm{~kg} \mathrm{ha}^{-1}$ de $\mathrm{N}$ amoniacal, aplicado na forma de dejetos enriquecidos com ${ }^{15} \mathrm{~N}$, pela cevada, foi de 37,27 e 14\%, respectivamente. O menor valor de RNad, quando os dejetos foram deixados na superfície do solo, foi justificado, por esses autores, pela maior volatilização de amônia nessa forma de aplicação. $\mathrm{O}$ menor aproveitamento de $\mathrm{N}$ pela cevada com a incorporação, quando comparada com injeção ao solo, foi atribuído ao aumento da imobilização de $\mathrm{N}$ resultante da incorporação dos dejetos ao solo.

Considerando-se que a incorporação dos dejetos, logo após a sua aplicação ao solo, reduz as perdas de $\mathrm{N}$ por volatilização de amônia (Rochette et al., 2001), era de se esperar que a incorporação desse material orgânico, conforme no presente trabalho, resultasse em maior RNad pelo milho em relação ao observado no tratamento com a aplicação dos dejetos em superfície. No entanto, em outro estudo realizado no mesmo experimento, durante o desenvolvimento da cultura do milho, Giacomini \& Aita (2008) verificaram que as quantidades de $\mathrm{N}$ mineral no solo não diferiram entre os tratamentos com e sem incorporação dos dejetos. Esse resultado pode indicar que a incorporação dos dejetos juntamente com a palha de aveia tenha aumentado a imobilização de $\mathrm{N}$ pela biomassa microbiana, durante a decomposição da palha no presente trabalho. Todavia, Giacomini et al. (2009) observaram que a quantidade de ${ }^{15} \mathrm{~N}$ proveniente do $\mathrm{N}$ amoniacal de DLS, encontrado no $\mathrm{N}$ orgânico do solo, não diferiu entre os sistemas com e sem incorporação. Assim, é provável que as condições climáticas, nos dois primeiros meses após a aplicação dos dejetos (Figura 1), tenham potencializado as perdas de $\mathrm{N}$ por volatilização de amônia, lixiviação e desnitrificação e, assim, contribuído para a menor recuperação, pelo milho, da fração amoniacal aplicada dos dejetos, o que aproximou os resultados dos dois sistemas de aplicação, no presente trabalho. Tais perdas podem ter sido potencializadas pela combinação de três 
fatores principais: a rápida nitrificação do $\mathrm{N}$ amoniacal, quando dejetos de suínos são aplicados ao solo (Aita et al., 2007); a ocorrência de alta pluviosidade, nos primeiros 37 dias após a aplicação dos dejetos, que totalizaram $364 \mathrm{~mm}$ de água no período (Figura 1); e a baixa demanda de $\mathrm{N}$ pela cultura do milho na fase inicial de desenvolvimento (Giacomini et al., 2004). Além de possíveis perdas de $\mathrm{N}$ por lixiviação e desnitrificação, também podem ter ocorrido perdas de $\mathrm{N}$ por escoamento superficial, principalmente quando os dejetos foram aplicados na superfície do solo, conforme constatou Basso (2003).

Deve-se destacar que, no presente trabalho, decorridas 4 horas da aplicação dos dejetos ao solo, ocorreu uma chuva de $40 \mathrm{~mm}$ (Figura 1), o que indica que parte do $\mathrm{N}$ aplicado com os dejetos pode ter sido perdida via escoamento superficial. Smith et al. (2001) destacaram que o potencial de perdas de $\mathrm{N}$ por escoamento superficial, após a aplicação dos dejetos, foi maximizado quando ocorreram eventos pluviais logo após sua aplicação.

A distribuição do ${ }^{15} \mathrm{~N}$ no perfil do solo, até a profundidade de $120 \mathrm{~cm}$, não diferiu entre os tratamentos, aos 127 dias após a aplicação do DLS (Figura 2). Aproximadamente $51 \%$ do N presente na camada $0-120 \mathrm{~cm}$ foi encontrado nos primeiros $10 \mathrm{~cm}$ do solo (17\% do $\mathrm{N}$ amoniacal aplicado), o que corrobora os resultados de outros estudos, em que a maior parte do ${ }^{15} \mathrm{~N}$ foi recuperada na camada superficial do solo e na forma orgânica (Morvan et al., 1997; Sorensen \& Amato, 2002; Chantigny et al., 2004).

A quantidade de ${ }^{15} \mathrm{~N}$ no perfil do solo foi pouco variável nas camadas abaixo de $0-10 \mathrm{~cm}$ (Figura 2). A presença de ${ }^{15} \mathrm{~N}$ em profundidade indica que $\mathrm{o}$ nitrato formado a partir da oxidação biológica do $\mathrm{N}$ amoniacal foi percolado no solo juntamente com a água de drenagem. Nesse mesmo experimento, Giacomini \& Aita (2008) avaliaram a distribuição de nitrato no perfil do solo. Aos 37 dias da aplicação de DLS não marcados, a quantidade de $\mathrm{NO}_{3}^{-}$na camada de $30-60 \mathrm{~cm}$ era significativamente superior à do tratamento sem dejetos. $\mathrm{O}$ rápido aparecimento de nitrato no perfil do solo ocorreu em razão da rápida nitrificação do $\mathrm{N}$ amoniacal dos dejetos (Aita et al., 2007) e da ocorrência de precipitações pluviais intensas, após a aplicação dos dejetos (Figura 1). O aproveitamento desse nitrato pelo milho depende do desenvolvimento e da velocidade de crescimento em profundidade de seu sistema radicular.
A avaliação da produção de massa de matéria seca de raízes de milho, na camada $0-120 \mathrm{~cm}$, na maturação fisiológica, identificou a presença de raízes na camada de $100-120 \mathrm{~cm}$, o que indica que o milho pode ter aproveitado também parte do $\mathrm{N}$ presente nas camadas mais profundas. No entanto, da quantidade total de massa de matéria seca de raízes encontrada até a profundidade de $0-120 \mathrm{~cm}$ (média de $2,36 \mathrm{Mg} \mathrm{ha}^{-1}$ ), a quantidade presente nas camadas abaixo de $20 \mathrm{~cm}$ representou apenas $14 \%$, com $1,4 \%$ na camada mais profunda $(100-120 \mathrm{~cm})$.

Os valores de ${ }^{15} \mathrm{~N}$ encontrados na camada mais profunda do perfil do solo confirmam que ocorreram perdas de $\mathrm{N}$ proveniente do amônio contido nos DLS. As quantidades de ${ }^{15} \mathrm{~N}$ encontradas em profundidade podem ter origem não apenas na lixiviação do ${ }^{15} \mathrm{~N}^{-\mathrm{NO}_{3}-}$, mas também na liberação de ${ }^{15} \mathrm{~N}$ em exudatos radiculares do milho e na provável presença de raízes finas, nas amostras de solo utilizadas para determinar o excesso isotópico em ${ }^{15} \mathrm{~N}$.

Não houve diferença nos valores de RNad, no sistema solo-planta, com a aplicação dos dejetos em plantio direto ou com preparo reduzido do solo (Tabela 2). Ao aplicar DLS em doses equivalentes a

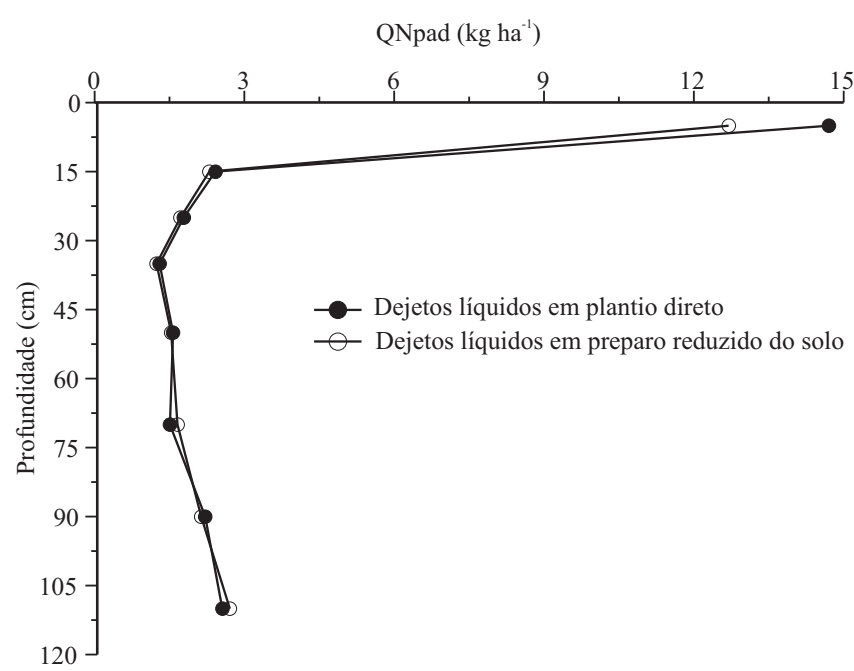

Figura 2. Quantidade de $\mathrm{N}$ proveniente do $\mathrm{N}$ amoniacal dos dejetos líquidos de suínos (QNpad), na camada de 0-120 cm do solo, na maturação fisiológica do milho (127 dias da semeadura), com a aplicação de dejetos em plantio direto e em preparo reduzido do solo. As médias entre os sistemas de plantio direto e preparo reduzido não diferem significativamente pelo teste $\mathrm{t}$, a $5 \%$ de probabilidade. 
$100 \mathrm{~kg} \mathrm{ha}^{-1}$ de $\mathrm{N}$ amoniacal marcados com ${ }^{15} \mathrm{~N}$ à cultura da cevada, Sorensen \& Amato (2002) encontraram valores de recuperação do ${ }^{15} \mathrm{~N}$ de $49 \%$, com a aplicação dos dejetos em superfície, e de $82 \%$, com incorporação ao solo. Esse valor de recuperação do ${ }^{15} \mathrm{~N}$ proveniente da aplicação dos dejetos em superfície, observado por esses autores, é similar ao encontrado no presente trabalho $(52,3 \%)$. No sistema com incorporação dos dejetos ao solo, o valor encontrado no presente trabalho foi $40 \%$ menor. Esta diferença deve estar relacionada, principalmente, às condições edafoclimáticas predominantes em cada estudo. Nos primeiros 60 dias após a aplicação dos dejetos, a precipitação pluvial acumulada, no presente estudo, foi de $475 \mathrm{~mm}$ (Figura 1), enquanto no trabalho de Sorensen \& Amato (2002) a precipitação foi de apenas $60 \mathrm{~mm}$. Jensen et al. (2000), ao incorporar ao solo dejetos de bovinos na dose $75 \mathrm{~kg} \mathrm{ha}^{-1}$ de $\mathrm{N}$ amoniacal marcado com ${ }^{15} \mathrm{~N}$, obtiveram recuperação do $\mathrm{N}$ amoniacal aplicado na colheita do trigo de $77 \%$ ( $32 \%$ na cultura e $45 \%$ na camada 0-100 cm do solo). Esses autores consideraram que a recuperação do $\mathrm{N}$ amoniacal foi relativamente elevada, para as condições em que foi realizado o estudo, e atribuíram o resultado à baixa precipitação após a incorporação dos dejetos ao solo. No presente trabalho, a elevada precipitação pluvial, logo após a aplicação dos dejetos, pode ter potencializado as perdas de $\mathrm{N}$ por escoamento superficial, por lixiviação e desnitrificação, o que teria diminuído a RNad.

Considerando-se que a contribuição da fração amoniacal foi determinada diretamente pela técnica de diluição isotópica de ${ }^{15} \mathrm{~N}$, é possível estimar, por diferença, a contribuição da fração orgânica dos dejetos e da matéria orgânica do solo (MO) não marcados, no fornecimento de $\mathrm{N}$ ao milho. Nos sistemas com preparo reduzido do solo e sem incorporação (plantio direto) dos dejetos, a contribuição de cada uma das fontes de $\mathrm{N}$ foi semelhante (Figura 3). Na média dos dois sistemas, a quantidade de $\mathrm{N}$ acumulada pelo milho, proveniente do $\mathrm{N}$ orgânico dos dejetos (QNpod), foi de $44,2 \mathrm{~kg} \mathrm{ha}^{-1}$, o que representa $53,8 \%$ da quantidade de $\mathrm{N}$ orgânico aplicado ao solo com os dejetos $\left(82,1 \mathrm{~kg} \mathrm{ha}^{-1}\right)$. Tais resultados indicam que os dejetos líquidos de suínos forneceram $56,3 \%$ do $\mathrm{N}$ absorvido pela parte aérea do milho, enquanto que o N proveniente da mineralização da $\mathrm{MO}$ contribuiu com $43,8 \%$.

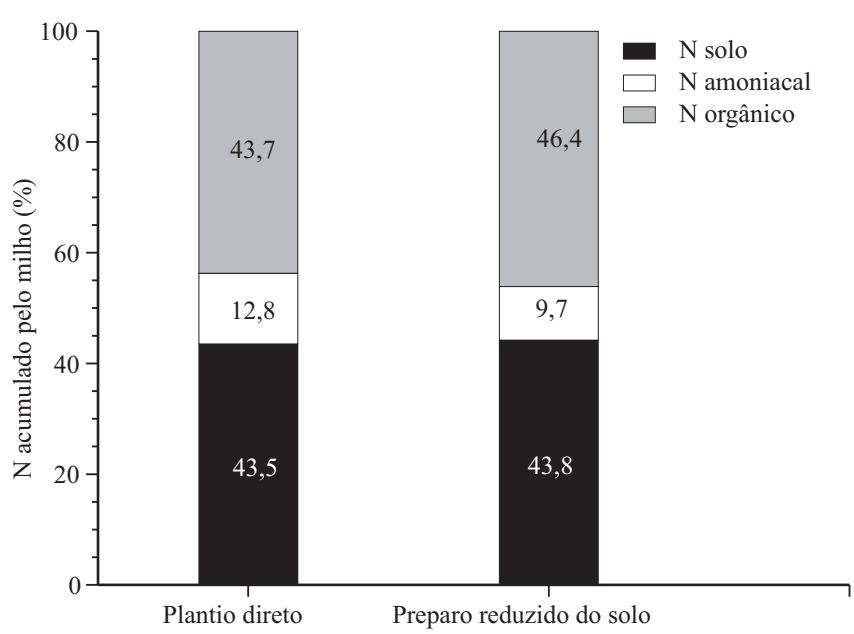

Figura 3. $\mathrm{N}$ acumulado na parte aérea do milho, proveniente do $\mathrm{N}$ amoniacal e do $\mathrm{N}$ orgânico dos dejetos e do $\mathrm{N}$ do solo, nos tratamentos com aplicação dos dejetos em plantio direto e em preparo reduzido do solo. As médias entre os sistemas de plantio não diferem significativamente pelo teste $\mathrm{t}$, a $5 \%$ de probabilidade.

\section{Conclusões}

1. A contribuição do $\mathrm{N}$ amoniacal dos dejetos de suínos no fornecimento de $\mathrm{N}$ ao milho é relativamente pequena, quando comparada à contribuição do $\mathrm{N}$ orgânico dos dejetos e do $\mathrm{N}$ do solo.

2. Aproximadamente metade do $\mathrm{N}$ amoniacal dos dejetos líquidos de suínos é perdida do sistema solo-planta, independentemente de seu uso em plantio direto ou preparo reduzido do solo.

\section{Agradecimentos}

À Coordenação de Aperfeiçoamento de Pessoal de Nível Superior e ao Comitê Francês de Avaliação de Cooperação Universitária com o Brasil, pelo auxílio financeiro concedido.

\section{Referências}

AITA, C.; GIACOMINI, S.J.; HÜBNER, A.P. Nitrificação do nitrogênio amoniacal de dejetos líquidos de suínos em solo sob sistema de plantio direto. Pesquisa Agropecuária Brasileira, v.42, p.95-102, 2007.

BASSO, C.J. Perdas de nitrogênio e fósforo com aplicação no solo de dejetos líquidos de suínos. 2003. 125p. Tese (Doutorado) - Universidade Federal de Santa Maria, Santa Maria.

CHANTIGNY, M.H.; ANGERS, D.A.; MORVAN, T.; POMAR, C. Dynamics of pig slurry nitrogen in soil and plant as determined with ${ }^{15} \mathrm{~N}$. Soil Science Society of America Journal, v.68, p.637-643, 2004.

DUETE, R.R.C.; MURAOKA, T.; SILVA, E.C. da; TRIVELIN, P.C.O.; AMBROSANO, E.J. Manejo da adubação nitrogenada e utilização 
do nitrogênio $\left({ }^{15} \mathrm{~N}\right)$ pelo milho em Latossolo Vermelho. Revista Brasileira de Ciência do Solo, v.32, p.161-171, 2008.

GIACOMINI, S.J.; AITA, C. Cama sobreposta e dejetos líquidos de suínos como fonte de nitrogênio ao milho. Revista Brasileira de Ciência do Solo, v.32, p.195-205, 2008.

GIACOMINI, S.J.; AITA, C.; CHIAPINOTTO, I.C.; HÜBNER, A.P.; MARQUES, M.G.; CADORE, F. Consorciação de plantas de cobertura antecedendo o milho em plantio direto. II - Nitrogênio acumulado pelo milho e produtividade de grãos. Revista Brasileira de Ciência do Solo, v.28, p.751-762, 2004.

GIACOMINI, S.J.; AITA, C.; JANTALIA, C.P.; URQUIAGA, S.; SANTOS, G.F. dos. Imobilização do nitrogênio amoniacal de dejetos líquidos de suínos em plantio direto e preparo reduzido do solo. Revista Brasileira de Ciência do Solo, v.33, p.41-50, 2009.

JENSEN, L.S.; PEDERSEN, I.S.; HANSEN, T.B.; NIELSEN, N.E. Turnover and fate of N-15-labelled cattle slurry ammonium-N applied in the autumn to winter wheat. European Journal of Agronomy, v.12, p.23-35, 2000.

MARSHALL, R.B.E.; WHITEWAY, J.N. Automation of an interface between a nitrogen analyser and an isotope ratio mass spectrometer. Analyst, v.110, p.867-871, 1985.

MORVAN, T.; LETERME, P.; ARSENE, G.G.; MARY, B. Nitrogen transformations after the spreading of pig slurry on bare soil and ryegrass using ${ }^{15} \mathrm{~N}$-labelled ammonium. European Journal of Agronomy, v.7, p.181-188, 1997.

PAUL, J.W.; BEAUCHAMP, E.G. Availability of manure slurry ammonium for corn using ${ }^{15} \mathrm{~N}$-labelled $\left(\mathrm{N}-\mathrm{NH}_{4}\right)_{2} \mathrm{SO}_{4}$. Canadian Journal of Soil Science, v.75, p.35-42, 1995.

PORT, O.; AITA, C.; GIACOMINI, S.J. Perda de nitrogênio por volatilização de amônia com o uso de dejetos de suínos em plantio direto. Pesquisa Agropecuária Brasileira, v.38, p.857-865, 2003.
POWLSON, D.S.; BARRACLOUGH, D. Mineralization and assimilation in soil-plant systems. In: KNOWLES, R.; BLACKBURN, T.H.; MELILLO, J.M. (Ed.). Nitrogen isotope techniques: isotopic techniques in plant soil and aquatic biology. London: Academic Press, 1993. p.209-242.

ROCHETTE, P.; CHANTIGNY, M.H.; ANGERS, D.A.; BERTRAND, N.; CÔTÉ, D. Ammonia volatilization and soil nitrogen dynamics following fall application of pig slurry on canola crop residues. Canadian Journal of Soil Science, v.81, p.515-523, 2001.

SCHERER, E.E. Utilização de esterco de suínos como fonte de nitrogênio: bases para adubação dos sistemas milho/feijão e feijão/ milho, em cultivos de sucessão. Florianópolis: EPAGRI, 1998. 49p. (EPAGRI. Boletim Técnico, 99).

SCHERER, E.E.; AITA, C.; BALDISSERA, I.T. Avaliação da qualidade do esterco líquido de suínos da região oeste catarinense para fins de utilização como fertilizante. Florianópolis: EPAGRI, 1996. 46p. (EPAGRI. Boletim Técnico, 79).

SISTEMA brasileiro de classificação de solos. Brasília: Embrapa Produção de Informação; Rio de Janeiro: Embrapa Solos, 1999. 412p.

SMITH, K.A.; JACKSON, D.R.; PEPPER, T.J. Nutrient losses by surface run-off following the application of organic manures to arable land. 1. Nitrogen. Environmental Pollution, v.112, p.41-51, 2001.

SORENSEN, P.; AMATO, M. Remineralisation and residual effects of $\mathrm{N}$ after application of pig slurry to soil. European Journal of Agronomy, v.16, p.81-95, 2002.

TEDESCO, M.J.; GIANELLO, C.; BISSANI, C.A.; BOHNEN, H.; VOLKWEISS, S.J. Análises de solo, plantas e outros materiais. 2.ed. Porto Alegre: Universidade Federal do Rio Grande do Sul, 1995. 174p. (UFRGS. Boletim Técnico, 5).

$\overline{\text { Recebido em } 16 \text { de fevereiro de } 2009 \text { e aprovado em } 3 \text { de julho de } 2009}$ 